\title{
The role of abscisic acid and water relations in drought responses of subterranean clover
}

\author{
X. Socias', M.J. Correia ${ }^{2}$, M. Chaves ${ }^{3}$ and H. Medrano ${ }^{1,4}$ \\ ${ }^{1}$ Departamento de Biologia Ambiental, Universitat de les Illes Balears-Instituto Mediterráneo de Estudios \\ Avanzados, 07071 Palma de Mallorca, Spain \\ 2 Universidade do Algarve, UCTA, Campus de Gambelas, 8000 Faro, Portugal \\ ${ }^{3}$ Departamento de Botanica, Instituto Superior de Agronomia, Universidade de Lisboa, 1399 Lisboa codex, \\ Portugal
}

Received 15 January 1997; Accepted 14 February 1997

\begin{abstract}
The role of water relations and abscisic acid (ABA) in the responses to drought were studied in a mediterranean forage crop, Trifolium subterraneum $L$. under field conditions. Soil and plant water status, leaf gas exchange parameters, and xylem sap ABA content were determined at different times during a long-term soil drying episode in irrigated and droughted plants. The diurnal time-courses of these parameters were also measured at the end of a drought period.

In response to soll drying stomatal conductance $(g)$ was reduced early to $50 \%$ that of irrigated plants before any substantial change in water potential was detected. A close logarithmic regression between photosynthesis rate (A) and $g$ was present. For the first weeks of drought the decline in $A$ was less pronounced than in $g$, thus increasing water use efficiency. Stomatal conductance during diumal time-courses showed no consistent relationships with respect to either ABA or leaf water potential. Throughout the experimental period dependence of $g$ on leaf water status was evident from the tight correlation $r^{2}=0.88$, $P<0.01)$ achieved between stomatal conductance and midday water potentlal, but the correlation was also high when comparing $g$ with respect to ABA content in xylem sap $\left(r^{2}=0.83, P<0.001\right)$. However, the stomata from drought acclimated plants were apparently more sensitive to xylem ABA content. For similar xylem ABA concentrations stomatal conductance was significantly higher in irrigated than in waterstressed plants.
\end{abstract}

Key words: Drought, stomatal conductance, water potential, abscisic acid.

\section{Introduction}

Plants growing in the Mediterranean region are often subjected to drought of variable duration and intensity. Even plants that avoid the summer period, as is the case of subterranean clover (Trifolium subterraneum L. an annual herbage plant growing from September to June), may suffer drought stress during autumn and late spring. In response to periods of water shortage, most plants have the ability to acclimate, combining morphological and physiological modifications which will improve their capacity to survive drought (Ludlow, 1989; Pereira and Chaves, 1993). Previous work by Socias and Medrano (1994) has shown that subterranean clover is able to reduce water loss dramatically by early stomatal closure as well as by reducing leaf appearance rate and leaf size and by increasing leaf senescence. On the other hand, in warm climates, a midday depression of stomatal conductance and carbon assimilation has been observed in various species (Tenhunen et al., 1987; Chaves et al., 1987), including subterranean clover (Vadell et al., 1995), which according to Cowan (1982), leads to an optimization of carbon acquisition in relation to water supply. Although this decrease can occur in well-watered plants (Correia et al., 1990), soil water depletion usually accentuates midday depression of gas exchange (Tenhunen et al., 1987; Chaves, 1991).

The causes for this depression are still far from being well understood, but a number of possible explanations may be put forward. One hypothesis to explain the afternoon depression in stomatal aperture would be the increase in the concentration of abscisic acid (ABA) in the transpiration stream which was found to be correlated with stomatal closure in various studies (Davies and

To whom correspondence should be addressed. Fax: +3471173184 .

C Oxford University Press 1997 
Zhang, 1991). However, the diurnal variation in stomatal aperture is rarely related with ABA concentration in the xylem sap in a simple way (Loveys, 1984; Wartinger et al., 1990; Correia et al., 1995). Recently, Tardieu and Davies (1992) and Correia et al. (1995) reported that the relationship between stomatal conductance and xylem ABA was not constant throughout the day, conductance being lower in the afternoon than in the morning for the same ABA concentration. It was suggested that an increase in leaf tissue dehydration by midday might be responsible for the changing sensitivity of stomata to $A B A$ during the day (Tardieu and Davies, 1992). A decrease in ABA catabolism during the day is another possibility to be taken into account (Trejo et al., 1993).

In the longer term, it seems well established that ABA plays a role as a positive long-distance signal from soil water deficits to stomata, often anticipating alterations in leaf water status (Jackson, 1993; Davies and Zhang, 1991). The role of xylem ABA in controlling leaf conductance, however, may decrease when soil drying and plant water deficit become severe (Correia and Pereira, 1995). The co-existence of negative signals (such as cytokinins) from soil drying has received support from the work by Wartinger et al. (1990), which found that xylem ABA tended to decrease late in the season, accompanying the depletion of soil water, but stomata still did not reopen. The hypothesis put forward was that a marked decrease in the activity of droughted-roots may lead to stomatal aperture becoming progressively limited by negative root signals. Therefore, the relative importance of positive and negative signals in the control of stomatal aperture may change during the season, negative signals becoming increasingly important as soil drying and injury to the root system increases (Davies and Zhang, 1991).

In a previous study with subterranean clover subjected to a slow-induced soil water depletion, it was shown that stomatal conductance was quickly reduced without any significant change in leaf water status (Socias and Medrano, 1994). This may indicate that a root signal is involved in this process. The present study was undertaken to evaluate the role played by xylem ABA and leaf water potential on stomatal regulation in this forage crop during a long-term acclimation to drought under field conditions in the Mediterranean region.

\section{Materials and methods}

\section{Crop and treatment characteristics}

Subterranean clover (Trifolium subterraneum ssp. brachycalycinum $\mathrm{cv}$. Clare) seeds $\left(5 \mathrm{~g} \mathrm{~m}^{-2}\right)$ were sown in small pots with a commercial horticulture substrate (29 January 1993). Two weeks after germination (2 March 1993), plantlets were transferred to the field, a clay-calcareous soil in Palma de Mallorca (Spain), in six simulated pasture plots (microswards) of $0.5 \times 0.5 \mathrm{~m}\left(250\right.$ plants $\left.\mathrm{m}^{-2}\right)$. Before planting, the experimental area was fertilized with $15 \mathrm{~g} \mathrm{~m}^{-2}$ of $\mathrm{N}, 6.1 \mathrm{~g} \mathrm{~m}^{-2}$ of $\mathrm{P}$ and $5.8 \mathrm{~g} \mathrm{~m}^{-2}$ of $\mathrm{K}$. Crop emergence and growth were satisfactory so that additional fertilization was not needed.

The experiment started when plants completely covered the ground ( 3 May $1993=$ day 0). From this date until the end of the experiment (10 June 1993) water stress was imposed on three adjacent plots by withholding watering. The control treatment was maintained near field capacity by irrigation with a micro-sprinkler system as well as by occasional rainfall (a total of $86 \mathrm{~mm}$ during the experiment). A plastic cover was placed over the water-stress plots when rainfall was expected, but immediately taken off after the rain stopped. On 8 June, a short, unexpected rainfall $(4 \mathrm{~mm})$ occurred before the cover was placed over the plots.

\section{Sampling}

The sampling dates to follow the soil drying effects were 3 May (last irrigation in droughted plots (day 0), 6, 17, 24, and 31 May and 10 June 1993. For each sampling time, measurements of midday water potential, gas exchange rates and predawn leaf water potential (taken the day after leaf gas exchange measurements) were done on six last fully expanded leaves from the top of the canopy in each treatment (two per plot).

\section{Plant water status}

Leaf water potential $(\psi)$ was determined, at predawn and midday, with a Scholander pressure chamber (Soil Moisture Equipment Corp. CA), following Faiz (1983).

\section{Gas exchange measurements}

Measurement of the rate of net photosynthesis $(A)$ and of transpiration $(E)$ were made on single leaves, with a $\mathrm{Li}$-Cor LI-6200 portable photosynthesis system, (Lincoln, NE) using a $1 / 41$ chamber, in the closed circuit mode. According to the manufacturer's instructions, stomatal conductance $(g)$ was calculated from transpiration rates, leaf and chamber temperature and chamber humidity, taking into account previous measurements of boundary layer resistance under similar chamber conditions. Leaf and chamber-air temperatures, humidity, and photosynthetic photon flux density (PPFD) were recorded. All measurements were taken on six attached, recently fully expanded leaves at the top of the canopy. During the experimental period, samples were always taken at around midday on sunny days $(P P F D=1800-2100 \mu \mathrm{mol}$ photons $\left.\mathrm{m}^{-2} \mathrm{~s}^{-1}\right)$.

\section{$A B A$ determinations}

Samples of xylem sap were collected from the same leaves where $\psi$ was measured at predawn. After determining the balance pressure an over pressure of $c .0 .2 \mathrm{MPa}$ was applied. After discarding the first xylem drop, the exudate subsequently produced was collected in Eppendorf tubes that were immediately frozen in liquid nitrogen. Samples were kept at $-80^{\circ} \mathrm{C}$ until analysis. Each sample (approximately $5 \mu \mathrm{l}$ per leaf) was analysed for ABA by ELISA (enzyme-linked immunosorbent assay), using the assay kits from Idetek (San Bruno, CA, USA). The assays were performed according to the instructions given in the Idetek manual. Before ELISA, each $2.5 \mu$ sample aliquot was diluted with TBS buffer (final volume $100 \mu \mathrm{l}$ ). Two replicate standard calibrations were made for each ELISA plate, using synthetic ( \pm )-ABA (Sigma), $50 \%$ of which was assumed to be the $(t)$ form. The samples were assayed for ABA without any previous purification. To test for possible non-specific interference in the analysis, $1 \mu \mathrm{l}$ of a pooled sample of xylem exudates 


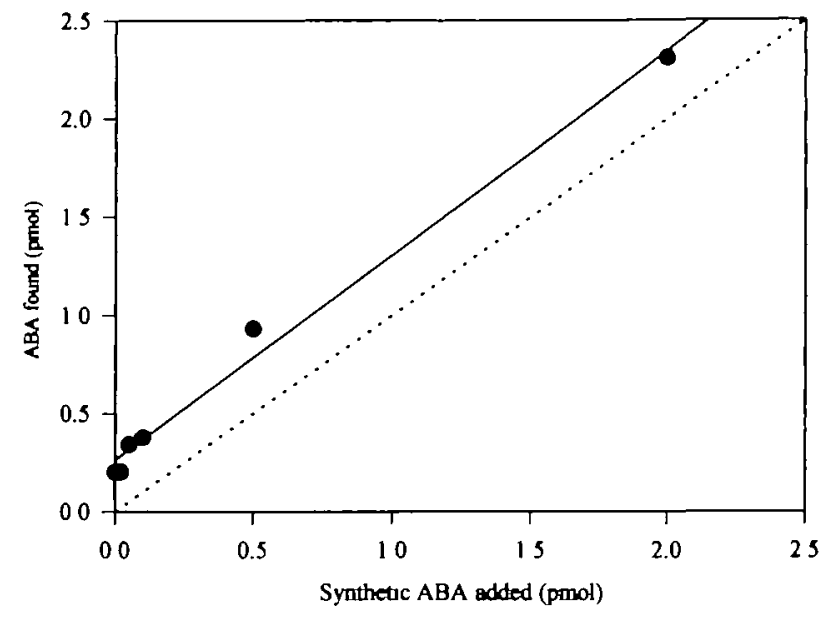

Flg. 1. Relationships between the apparent abscisic acid concentration quantified by an ELISA immunoassay and the amount of synthetic ABA added to the samples: dotted line, synthetic ABA alone; full line and points, synthetic ABA plus $1 \mu$ l of a pooled sample.

was assayed in the presence of increasing amounts of synthetic ABA. When the apparent hormone concentration was plotted against the amount of ABA standard added, a straight line, $\left(r^{2}=0.987, P<0.0001\right)$ was obtained with a slope not significantly different from unity $(F=0.046, P=0.835)$, i.e. a line parallel to the line of the standard alone (Fig. 1). This indicated that no non-specific interference was present (Pengelly, 1985). The contamination of expressed sap with phloem was assessed by quantifying sucrose using a spectrophotometric enzymecoupled assay (Jones et al., 1977) and it was found to be negligible.

\section{Daily time-courses}

Near the end of the experimental period, daily time-courses of water potential, $\mathrm{ABA}$, photosynthesis and related parameters were measured in irrigated and drought acclimated leaves on two consecutive sunny days (June 2 and 3 ). Measurements were made several times during the day on 6 leaves ( 3 per treatment and day) of the upper part of the canopy.

\section{Results}

\section{Environmental conditions and crop growth}

Environmental conditions during the growth period were typical of a Mediterranean spring (Table 1). Soil water was gradually reduced in non-irrigated plots. Crop growth was satisfactory achieving at the end of the experiment, around $40 \mathrm{~cm}$ height, and $861 \mathrm{~g} \mathrm{~m}^{-2}$ of dry mass ( $L A I$ 2.2 ) in irrigated plots whereas in the droughted ones

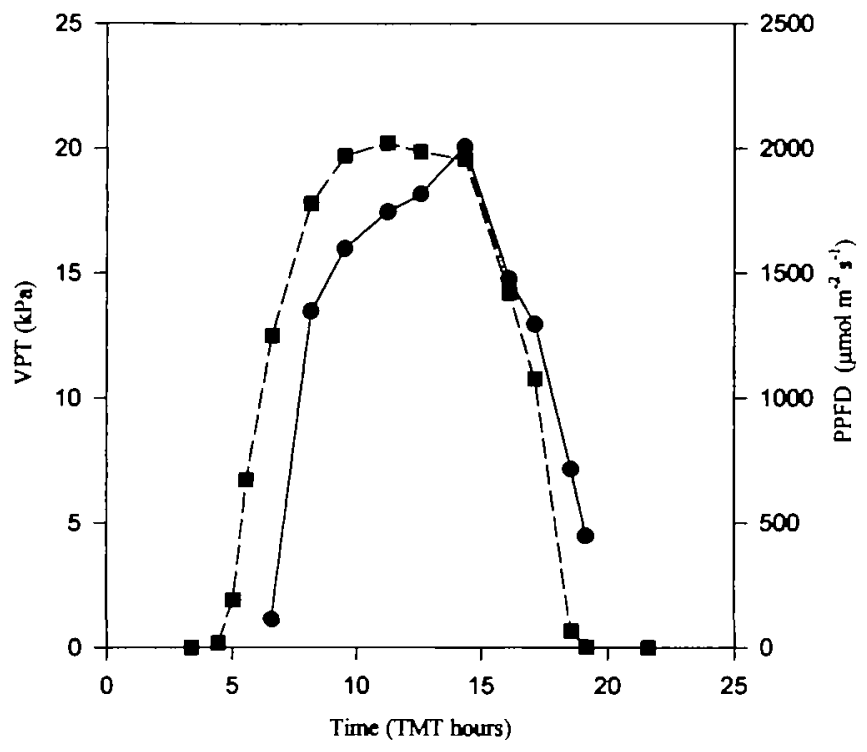

Fig. 2. Diurnal time-courses of environmental conditions: vapour pressure tension (VPT) and photosynthetic photon flux density $(P P F D)$. Points (circles for $V P T$, squares for $P P F D$ ) are average and standard error of six values (three from each day) taken during the sampling period.

height was around $20 \mathrm{~cm}$, and dry mass $387 \mathrm{~g} \mathrm{~m}^{-2}$ ( LAI 0.35 , because of a high number of dried leaves). For the diurnal time-course measurements the variations in photosynthetic photon flux density ( $P P F D)$, and vapour pressure tension $(V P T)$ followed a typical pattern for a cloudless day of late spring, in the Mediterranean region (Fig. 2).

\section{Water potential}

Predawn and midday water potentials showed significantly lower values in non-irrigated plants than in controls (Fig. 3), from the 3rd sampling date (day 14). During the drought acclimation period, in irrigated plants predawn values remained quite uniform, whereas midday $\psi$ clearly declined (from -1 to $-2 \mathrm{MPa}$ ), corresponding to an increase in the daily atmospheric water vapour demand. Steeper decreases in $\psi$ were recorded in nonirrigated plants: predawn leaf water potential showed an abrupt decrease between 14 and $21 \mathrm{~d}$, followed by a small recovery with a stabilization to values around $-1.4 \mathrm{MPa}$; midday $\psi$ decreased continuously reaching $-3.5 \mathrm{MPa}$ at the last sampling date. The difference in midday $\psi$ between

Table 1. Monthly average $\pm S E$ of daily evapotranspiration, irradiance, maximal and minimal temperatures during the growth period

\begin{tabular}{llllr}
\hline Month & $\begin{array}{l}\text { Evapotranspiration } \\
\left(1 \mathrm{~m}^{-2} \mathrm{~d}^{-1}\right)\end{array}$ & $\begin{array}{l}\text { Irradiance } \\
\left(\mathrm{MJ} \mathrm{m}^{-2} \mathrm{~d}^{-1}\right)\end{array}$ & $\begin{array}{l}\text { Maximum temperature } \\
\left({ }^{\circ} \mathrm{C}\right)\end{array}$ & $\begin{array}{l}\text { Mininum temperature } \\
\left({ }^{\circ} \mathrm{C}\right)\end{array}$ \\
\hline March & $2.6 \pm 0.2$ & $15.5 \pm 6.7$ & $14.8 \pm 0.5$ & $7.2 \pm 0.2$ \\
April & $2.9 \pm 0.3$ & $18.9 \pm 7.0$ & $17.5 \pm 0.6$ & $9.6 \pm 0.5$ \\
May & $3.4 \pm 0.5$ & $23.4 \pm 5.3$ & $22.4 \pm 0.4$ & $13.4 \pm 0.2$ \\
June & $4.0 \pm 0.3$ & $26.8 \pm 6.1$ & $25.2 \pm 0.3$ & $17.4 \pm 0.3$ \\
\hline
\end{tabular}




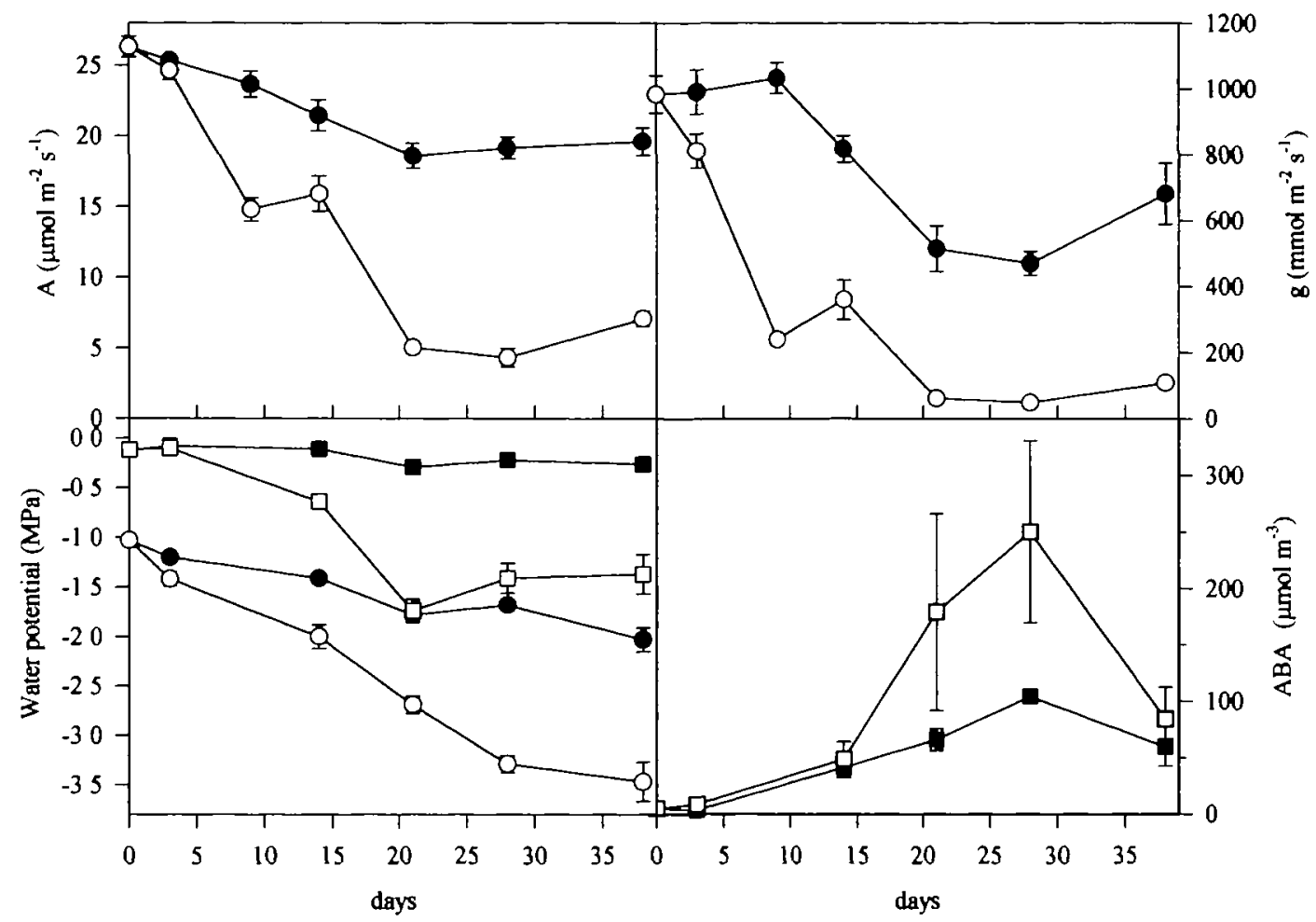

Fig. 3. Effects of soil drying on net $\mathrm{CO}_{2}$ assimilation rate $(A)$ stomatal conductance $(g)$, determined at midday, leaf water potential determined at predawn (squares) or at midday (circles) and on predawn ABA concentration in xylem sap. Points are averages of six recently expanded leaves at the top of the canopy of irrigated (closed symbols) or droughted (open symbols) plots. Vertical bars indicates standard error of the means ( $n$ m 6 ).

irrigated and non-irrigated plants increased throughout the experiment.

The diurnal variation of leaf water potential was similar for both irrigated and non-irrigated plants, but with values $0.5-0.8 \mathrm{MPa}$ lower in the non-irrigated ones (Fig. 4). Such higher $\psi$ could be due to the abundant dew over the leaves, which was present both days, and also interfered with $g$ determinations in first morning hours.

\section{Stomatal conductance and leaf photosynthesis}

Stomatal conductance was rapidly decreased in response to soil drying (Fig. 3). After $3 \mathrm{~d}$ without irrigation significantly lower values of $g$ were recorded in nonirrigated than in well-watered plants. This early reduction in $g$ was followed by a sharp reduction by day 14 , leading to minimum values around $100 \mathrm{mmol} \mathrm{m} \mathrm{m}^{-2} \mathrm{~s}^{-1}$ which were maintained until the end of the experimental period (Fig. 5). Irrigated plants also showed a gradual $g$ reduction, presumably as a response to an increased water demand associated with the progressively longer, hotter and drier days (see ETP in Table 1).

In both well-watered and non-irrigated plants, the variation in net photosynthetic rate $(A)$ during the experimental period (Fig. 3) was similar to the variation of $g$, although less pronounced, therefore a tight correlation was found between $A$ and $g$ (Fig. 6).
Due to dew deposition on the leaves, $g$ could not be measured during the first hours of the day (Fig. 4). For irrigated plots there was a slow decrease from midmorning to the evening hours. In water-stressed leaves, low values of $g$ were recorded at all times during the measurement period.

Net photosynthetic rate from irrigated plants were maximal at mid-morning, decreasing afterwards, but the depression in $A$ throughout the day was less pronounced than in the case of $g$ (Fig. 4). During the early hours of daylight, $A$ values for water-stressed and control plants were similar. Afterwards, a continuous decline of $A$ in stressed plants led to midday values $65 \%$ lower than in irrigated plants. In the former a small afternoon recovery was also present.

\section{$A B A$ in xylem sap}

As Fig. 3 shows, the ABA content in the xylem sap collected at predawn increased during the soil drying episode. A large increase in ABA content during the experiment was detected even in samples collected from irrigated plants (from 4 to $104 \mu \mathrm{mol} \mathrm{m}^{-3}$ ). Last point reduction could be explained as a little recovery after the short rainfall.

The mean values of midday stomatal conductance decreased exponentially as the ABA concentration in predawn xylem sap increased throughout the experimental 


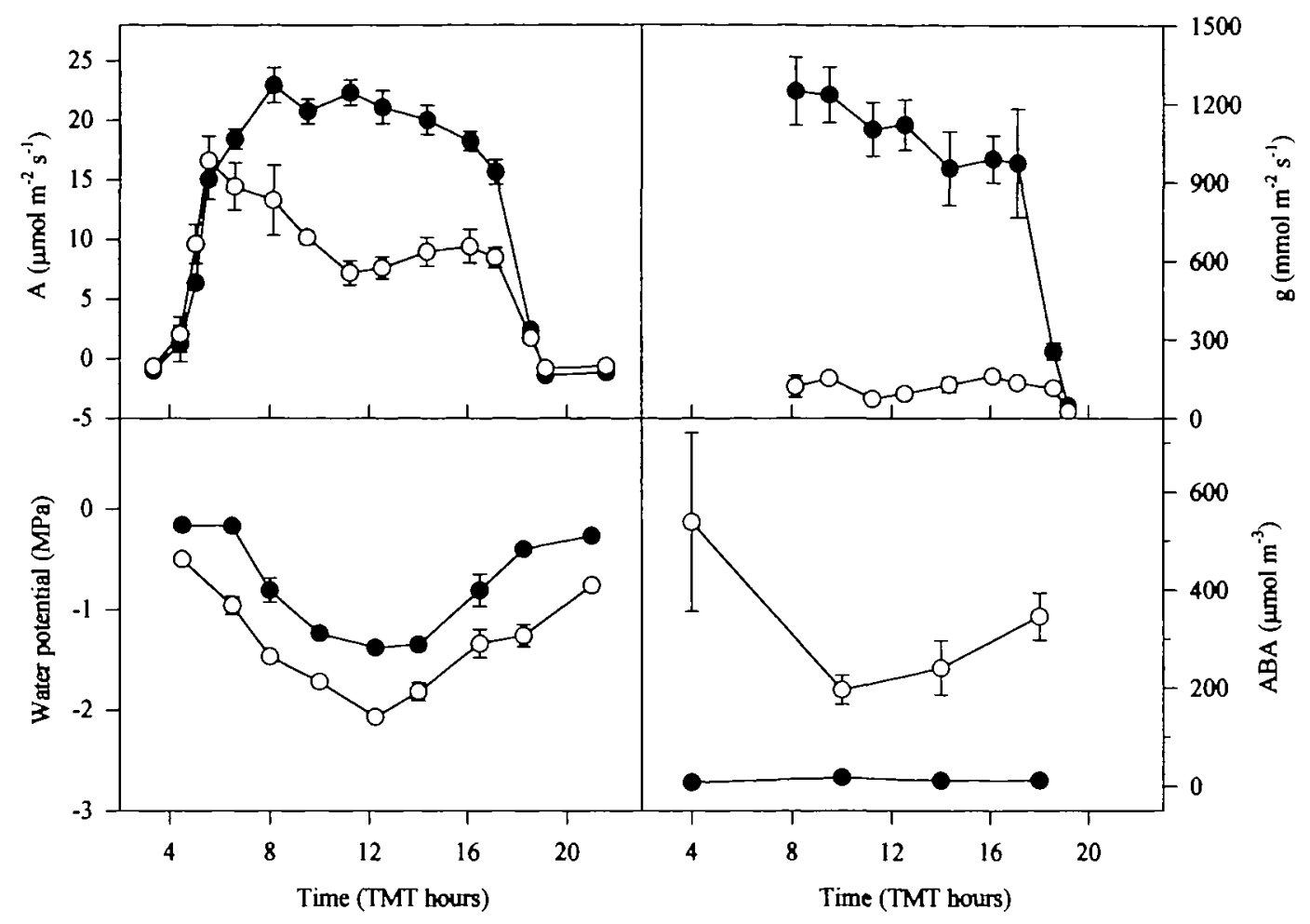

Flg. 4. Diurnal time-courses of net $\mathrm{CO}_{2}$ assimilation rate $(A)$ stomatal conductance $(g)$, leaf water potential, and ABA concentration in xylem sap, determined on two consecutive days at the end of the soil drying experiment. Points are average of six values (three from each day) taken from recently expanded leaves of the top of the canopy of irrigated (closed symbols) or droughted (open symbols) plots. Vertical bars indicates standard error of the means.

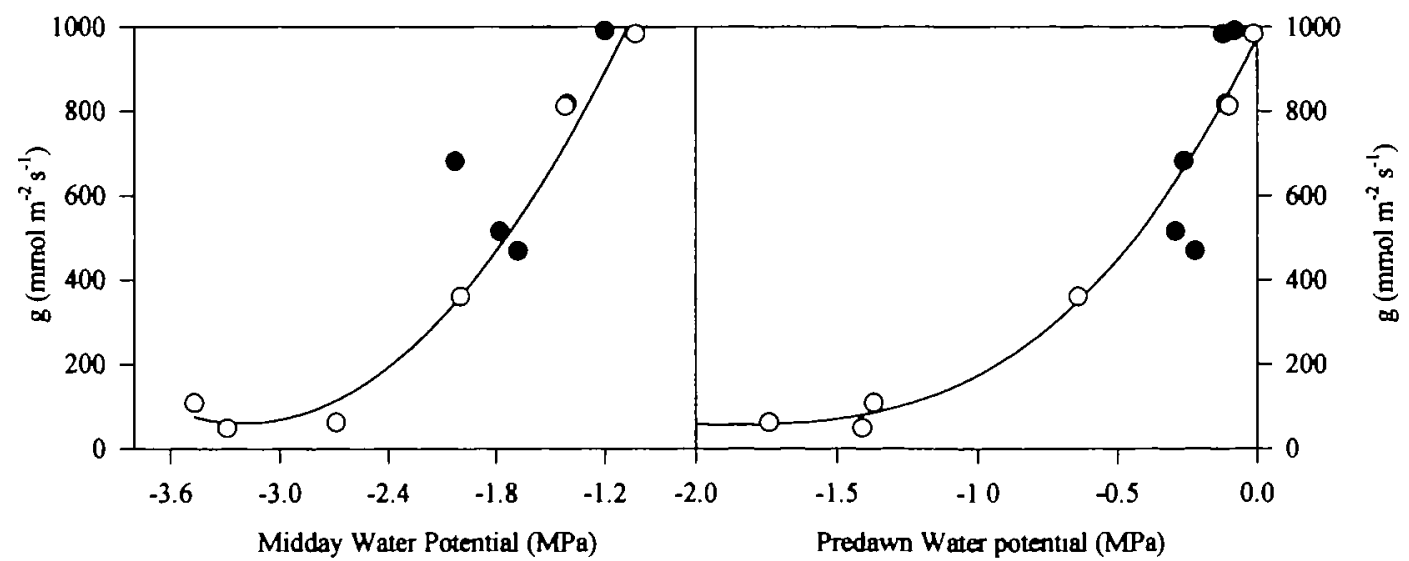

Fig. 5. Relationship between stomatal conductance at midday $(g)$ and leaf water potential determined at predawn (a) and midday (b) in irrigated (closed symbols) and droughted (open symbols) plots, during the soil drying experiment. Equations, regression coefficients $\left(r^{2}\right)$ and significance levels $(P)$ were as follows: $y=1071.3 \times 10^{(0.779 x)}, r^{2}=0.947, P=0.01$ (for predawn water potential) and $y=3493.0 \times 10^{(0.523 x)}, r^{2}=0.849, P=0.01$ (for midday water potential).

period both in stressed and unstressed plants. Joint plot of drought and irrigated values showed high, significant correlation $\left(r^{2}=0.834, P<0.001\right)$. However, as shown in Fig. 7 , this relationship was apparently changed by the watering regime: for a similar ABA content stomatal conductance was significantly higher in irrigated than in water-stressed plants. Drought-induced increase of apparent stomatal sensitivity to xylem ABA was confirmed by covariance analysis of the linear relationship between $g$ and the logarithm of xylem [ABA], which showed that the slope of the relationship were significantly different between treatments $(F=8.12, P=0.022)$.

The decline in $g$ that was observed in well-watered plants throughout the day (Fig. 4) was not associated with increased concentrations of ABA in xylem sap: as shown in Fig. 4, the ABA concentration in the xylem sap 


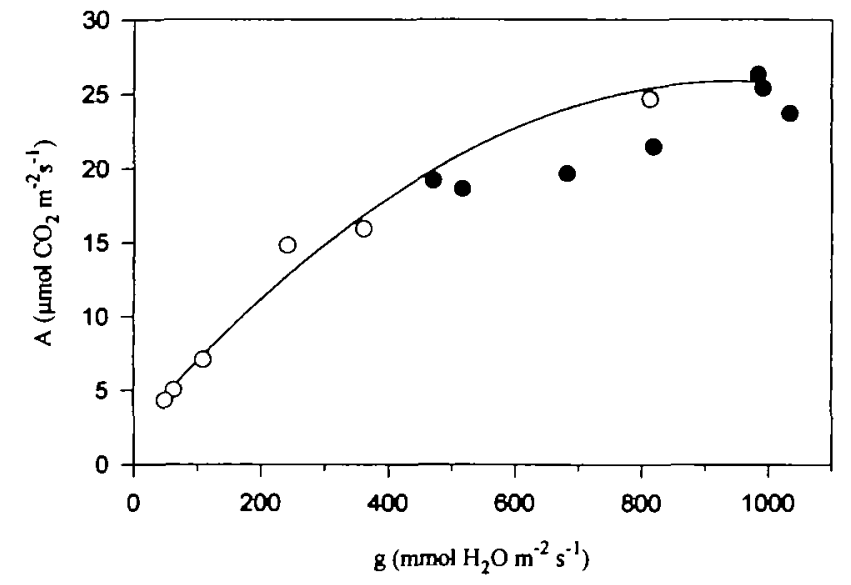

Fig. 6. Relationship between photosynthetic rate $(A)$ and stomatal conductance $(g)$ determined in irrigated (closed symbols) and droughted (open symbols) plots, during the soil drying experiment. The fitted equation, regression coefficient $\left(r^{2}\right)$ and significance level $(P)$ were: $y=$ $-26.404+17.285 \log (x), r^{2}=0.979, P=0.01$.

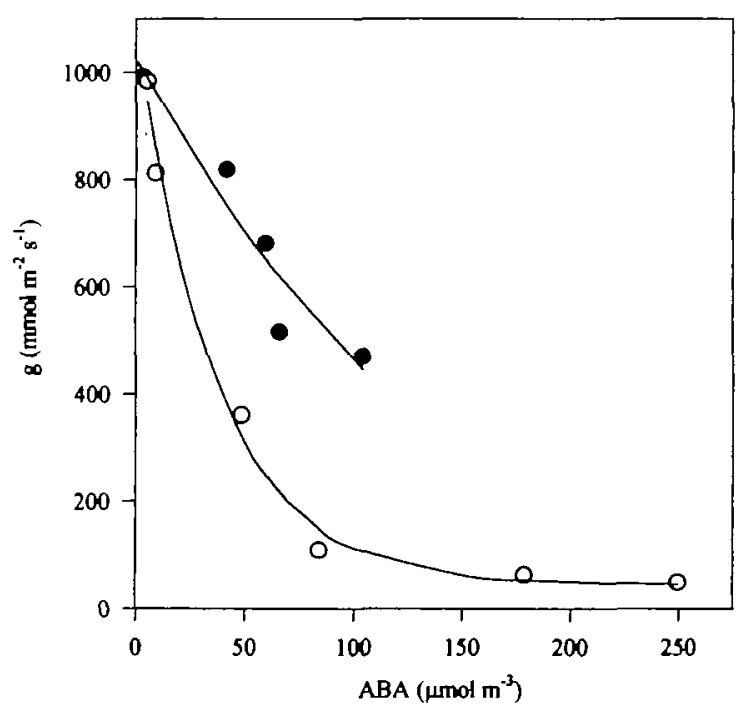

Fig. 7. Relationship between stomatal conductance at midday $(g)$ and the ABA concentration in xylem sap determined at predawn in irrigated (closed symbols) and droughted (open symbols) plants, during the soil drying experiment. The fitted equations, regression coefficients $\left(r^{2}\right)$ and significance level $(P)$ were as follows: $y=-0.24+1.26 \exp (-0.006 x), r^{2}=$ $0.935, P=0.017$ (for irrigated plots) and $y=0.04+1.04 \exp (-0.03 x)$, $r^{2}=0.991, P=0.0008$ (for non-irrigated plots).

of well-watered plants remained very low during the day ranging between 6 and $12 \mu \mathrm{mol} \mathrm{m}{ }^{-3}$. It seems likely that low predawn values (below the ones recorded in the last sampling dates) could be due to the dew deposition over blades and petioles. ABA flux, calculated from xylem sap concentration and $E$, gave maximum values for the $10.00 \mathrm{~h}$ sampling time $\left(3.02 \times 10^{-6} \mu \mathrm{mol} \mathrm{m}^{-2} \mathrm{~s}^{-1}\right)$ coincident with the highest $g$ values.

A significant diurnal change in xylem ABA concentration was detected only in water-stressed plants (Fig. 4). On these plants, the ABA content in xylem sap decreased during the early morning hours, reaching a minimum value at mid morning, and increasing slightly throughout the rest of the day (from around 200 to $370 \mu \mathrm{mol} \mathrm{m}^{-3}$ ). Despite this much lower transpiration rate, the calculated ABA flux of stressed plants was always higher than for irrigated plants, being maximum $\left(16.20 \times 10^{-6} \mu \mathrm{mol} \mathrm{m} \mathrm{m}^{-2}\right.$ $\mathrm{s}^{-1}$ ) for the $10.00 \mathrm{~h}$ sampling time.

\section{Discussion}

The present data confirm previous results obtained by Socias and Medrano (1994), and Vadell et al. (1995) in Trifolium subterraneum field assays, representative of common pasture under Mediterranean conditions. These authors found that stomata of this species quickly respond to a gradual soil water depletion. Experiments in pots, under three contrasting environmental conditions (Socias et al., 1997) showed that $g$ variations were more dependent on soil water availability than any other water relation parameter.

Net photosynthesis was well correlated with stomatal conductance (Fig. 6). An early increase in the instantaneous water-use efficiency occurred as stress developed, as found previously (Socias and Medrano, 1994). In fact, in plants under moderate water deficits (at sampling times 2 and 3), net photosynthesis rate remained at around $70 \%$ of irrigated plants with transpiration losses reduced to less than $40 \%$. These results also indicate that photosynthesis is very resilient to slowly developing soil water deficits under field conditions, stomatal closure being the main limiting factor down to very low tissue water contents, as shown in other species (Chaves, 1991; Cornic, 1994).

On a diurnal basis, the decline in $g$ often recorded by the middle of the day under Mediterranean conditions was not evident for well-watered subterranean clover plants (Fig. 4). Due to the almost total closure of stomata during the day in water-stressed plants, midday depression of stomatal conductance was hardly observed. In contrast, a clear midday depression of $A$ was apparent in waterstressed plants that could not be fully explained by changes in $g$ and may also be dependent on some metabolic factor(s). This is a still open question, but there are some suggestions that a build-up of sugars (Quick et al., 1992; Vadell et al., 1995), or a down-regulation of photosystem II as a result of excess light (Correia et al., 1990) could be involved in this response. In the wellwatered plants almost no depression of photosynthesis by midday was apparent, confirming that water deficits enhance such an effect (Tenhunen et al., 1987), presumably by reducing energy consumption through carbon assimilation and increasing the extent of energy dissipation.

The concentration of ABA in the xylem sap of droughted conifer saplings (Jackson et al., 1995) and 
field-grown Ceanothus thyrsiflorus plants (Tenhunen et al., 1994) has been reported to increase from predawn to midday. In contrast, and similarly to what was found by Tardieu et al. (1992) in field-grown maize plants, the concentration of ABA in the xylem sap of droughted subterranean clover plants decreased during the early morning (Fig. 4). However, stomatal conductance of water-stressed plants remained low even by mid-morning, when the concentrations of ABA were minimal. In contrast, well-watered plants exhibited a gradual decline in $g$ throughout the day, and this occurred despite the concentration of $\mathrm{ABA}$ in the xylem sap and calculated $\mathrm{ABA}$ fluxes of those plants remaining very low (below waterstressed values) during the day (Fig. 4). The present data are in agreement with the findings of Correia et al. (1995) showing that the xylem ABA concentration does not explain diurnal time variations in stomatal conductance in grapevines growing in the field, either droughted or irrigated. No consistent relationships were also found between diurnal changes in xylem ABA concentration and $g$ in field-grown almond trees (Wartinger $e t$ al., 1990) and maize plants (Tardieu et al., 1992). Nevertheless, as Jackson (1993) pointed out, changes in transpiration flux should be taken into account to evaluate the ABA flux arriving in the leaves. The calculated ABA flux did not show the expected negative correlation with respect to $g$, even allowing for the suggestion of Loveys (1984) that the highest ABA fluxes could precede the lowering in stomatal conductance.

Concerning the role of $\mathrm{ABA}$ in the long-term response of subterranean clover to water deficits, although the mean values of midday stomatal conductance decreased exponentially as the ABA concentrations in xylem sap increased throughout the experimental period, the decline in $g$ as soil dried was paralleled by the development of leaf water deficit. The observed tight correlation between midday leaf $\psi$ and $g\left(r^{2}=0.85\right.$, Fig. 5) may suggest that xylem ABA is not controlling stomatal behaviour. However, in a recent work with sunflower plants, Tardieu et al. (1996) proposed that daytime leaf water potential is correlated with leaf conductance without having a controlling effect on stomatal behaviour. According to Tardieu et al. (1996), if $g$ depends on xylem ABA concentration alone, correlations between $g$ and $\psi$ would be expected as a result of the relationship between water flux and the gradient of water potential through the plant. In the present study it was found that, for similar [ABA] in xylem sap, $g$ was higher in irrigated than in water-stressed plants (Fig. 7). This indicates that the stomata from drought-acclimated plants are apparently more sensitive to xylem ABA rather than stomatal conductance being controlled exclusively by the changes in ABA concentration in xylem sap. It is possible that the concentration of ABA in xylem sap may change from predawn (when ABA samples were taken) to midday (when $g$ was meas- ured), and the kinetics of ABA may be different between stressed and non-stressed plants. As shown in Fig 4, the concentration of $\mathrm{ABA}$ in the xylem sap of droughted plants tended to decrease during the morning, but it was maintained constant in watered plants. Therefore, if stomatal conductance was plotted against the concentration of $\mathrm{ABA}$ in the xylem sap at midday rather than at predawn this would probably further emphasize the drought-induced increase in the apparent stomatal responsiveness to xylem ABA.

It remains to be seen whether the apparent droughtinduced increased stomatal sensitivity to ABA is a consequence of lower leaf water potential per se (Tardieu and Davies, 1992), decreased ABA catabolism (Trejo et al., 1993), and/or changes in the composition of xylem sap compounds others than ABA (Schurr et al., 1992).

\section{Conclusions}

The data presented in this paper indicate a type of acclimatory response to drought in this herb species that is similar to that observed in other Mediterranean shrub and tree species (Tenhunen et al., 1987; Chaves et al., 1987). These characteristics seem therefore to be important also for a natural Mediterranean pasture such as subterranean clover. An increase in wate use efficiency occurred under moderate stress in these plants due to the maintenance of photosynthesis when stomata were already closing. Nevertheless, carbon uptake by the leaves was subjected to some metabolic down-regulation during the day, which was enhanced under water-stress. As to the involvement of $\mathrm{ABA}$ in the stomatal responses of subterranean clover to water deficits, it seemed to depend on whether long-term or short-term (diurnal) effects were considered. At the diurnal level, this root signal was not able to explain changes in $g$. In the long-term however, the decline in stomatal conductance as soil dried was associated with increased concentrations of $A B A$ in xylem sap, together with increased stomatal responsiveness to this root signal.

\section{Acknowledgements}

This work was supported by the UE grant AIR CT93-1031 and the Acciones Integradas Hipano-Portuguesas No.33B (1993-94).

\section{References}

Chaves MM. 1991. Effects of water deficits on carbon assimilation. Journal of Experimental Botany 42, 1-16.

Chaves MM, Harley PC, Tenhunen JD, Lange OL. 1987. Gas exchange studies in two Portuguese grapevine cultivars. Physiologia Plantarum 70, 639-47.

Cornic G. 1994. Drought stress and light effects on leaf photosynthesis. In: Baker NR, Boyer E, eds. Photoinhibition 
1288 Socias et al.

of photosynthesis: from molecular mechanisms to the field. Oxford: Bios Scientific Publication, 297-313.

Correia MJ, Pereira JS. 1995. The control of leaf conductance of white lupin by xylem ABA concentration decreases with the severity of water deficits. Journal of Experimental Botany 46, 101-10.

Correia MJ, Chaves MM, Pereira JS. 1990. Afternoon depression in photosynthesis in grapevine leaves-evidence for a high light stress effect. Journal of Experimental Botany 41, 417-26.

Correia MJ, Pereira JS, Chaves MM, Rodrigues ML, Pacheco CA. 1995. ABA xylem concentrations determine maximum daily leaf conductance of field-grown Vitis vinifera L. plants. Plant, Cell and Environment 18, 511-21.

Cowan IR. 1982. Regulation of water use in relation to carbon gain in higher plants. In: Lange OL, Nobel PS, Osmond CB, Ziegler H, eds. Physiological plant ecology. II. Water relations and carbon assimilation, Encyclopedia of plant physiology, Vol. 12B. Berlin: Springer-Verlag, 589-614.

Davies WJ, Zhang J. 1991. Root signals and the regulation of growth and development of plants in drying soil. Annual Review of Plant Physiology 42, 55-76.

Faix, SMA. 1983. Use of pressure bomb in the determination of soil water potential. Plant and Soil 73, 257-64.

Jackson MB. 1993. Are plant hormones involved in root to shoot communication? Advances in Botanical Research 19, 103-87.

Jackson GE, Irvine J, Grace J, Khalil AAM. 1995. Abscisic acid concentrations and fluxes in droughted conifer saplings. Plant, Cell and Environment 18, 13-32.

Jones MGK, Outlaw WH, Lowry OH. 1977. Enzymic assay of $10^{-7}$ to $10^{-4}$ moles of sucrose in plant tissues. Plant Physiology 60, 379-83.

Loveys BR. 1984. Diurnal changes in water relations and abscisic acid in field-grown Vitis vinifera cultivars. III. The influence of xylem-derived abscisic acid on leaf gas exchange. New Phytologist 98, 563-73.

Ludlow MM. 1989. Strategies of response to water stress. In: Kreeb KH, Richter H, Hinckley TM, eds. Structural and functional responses to environmental stresses: water shortage. The Hague: SPB Academic Publishing, 269-82.

Pengelly WL. 1985. Validation of immunoassays. In: Bopp M, ed. Plant growth substances. Berlin: Springer-Verlag, 35-43.

Pereira JS, Chaves MM. 1993. Plant water deficits in Mediterranean ecosystems. In: Smith JAC, Griffiths $\mathrm{H}$, eds. Plant responses to water deficits-from cell to community. Oxford: Bios Scientific Publlications, 237-51.
Quick WP, Chaves MM, Wendler R, David M, Rodrigues ML, Passarinho JA, Pereira JS, Adcock MD, Leegood RC, Stitt M. 1992. The effect of water stress on photosynthetic carbon metabolism in four species grown under field conditions. Plant, Cell and Environment 15, 25-35.

Schurr U, Gollan T, Schulze ED. 1992. Stomatal response to drying soil in relation to changes in the xylem sap composition of Helianthus annuus. II. Stomatal sensitivity to abscisic acid imported from the xylem sap. Plant, Cell and Environment $15,561-7$.

Socias FX, Medrano H. 1994. Drought acclimation in field growing subterranean clover plants. Agronomie 2, 141-8.

Socias FX, Pol A, Aguiló F, Vadell J, Medrano H. 1997. Effects of rapidly and gradually induced water stress on plan tresponse in subterranean clover leaves. Journal of Plant Physiology 150, 212-19.

Tardieu F, Davies WJ. 1992. Stomatal response to abscisic acid is a function of current plant water status. Plant Physiology 98, 540-9.

Tardieu F, Zhang J, Davies WJ. 1992. What information is conveyed by an $\mathrm{ABA}$ signal from maize roots in a drying field? Plant, Cell and Environment 15, 185-91.

Tardieu F, Lafarge T, Simonneau T. 1996. Stomatal control by fed or endogenous xylem ABA in sunflower: interpretation of correlations between leaf water potential and stomatal conductance in anisohydric species. Plant, Cell and Environment 19, 75-84.

Tenhunen JD, Pearcy RW, Lange OL. 1987. Diurnal variations in leaf conductance and gas exchange in natural environments. In: Zeiger E, Farquhar GD, Cowan IR, eds. Stomatal function. Stanford University Press, 324-51.

Tenhunen JD, Hanano R, Abril M, Weiler EW, Hartung W. 1994. Above- and below-ground environmental influences on leaf conductance of Ceanothus thyrsiflorus growing in a chaparral environment: drought response and the role of abscisic acid. Oecologia 99, 306-14.

Trejo CL, Davies WJ, Ruiz LMP. 1993. Sensitivity of stomata to abscisic acid. An effect of the mesophyll. Plant Physiology 102, 497-502.

Vadell J, Cabot C, Medrano H. 1995. Diurnal time-course of leaf gas exchange rates and related characters in drought acclimated and irrigated Trifolium subterraneum. Australian Journal of Plant Physiology 22, 461-9.

Wartinger A, Heilmeier H, Hartung W, Schulze ED. 1990. Daily and seasonal courses of leaf conductance and abscisic acid in the xylem sap of almond trees [Prunus dulcis (Miller) D.A. Webb] under desert conditions. New Phytologist 116, 581-7. 